\title{
Detection of fine-scale relationships between species composition and biomass in grassland
}

\author{
M. Kertész ${ }^{1}$, B. Lhotsky ${ }^{1}$ and I. Hahn ${ }^{2}$ \\ ${ }^{1}$ Institute of Ecology and Botany, Hungarian Academy of Sciences, Alkotmány u. 2-4, 2163 Vácrátót, Hungary. \\ E-mail:kmiki@botanika.hu \\ ${ }^{2}$ Department of Plant Taxonomy and Ecology, L. Eötvös University, Pázmány P. s. 1/c, H-1117 Budapest, \\ Hungary.Fax: 3613812 188, E-mail: hahn@ludens.elte.hu
}

Keywords: Association, Diversity, Information statistics, NDVI, Non-destructive sampling.

\begin{abstract}
We elaborated and tested a novel operative framework for sampling and analysing fine-scale pattern of plant composition and biomass. We combined presence/absence sampling of plant species with non-destructive biomass estimation. In an open perennial sand grassland, we used $46 \mathrm{~m}$ long circular transects consisting of $0.05 \mathrm{~m}$ by $0.05 \mathrm{~m}$ adjoining elementary sampling units. This arrangement allows us to scale across a range of 0.05 to $20 \mathrm{~m}$. For measuring aboveground green biomass, we applied digital camera sensitive to red and near infrared parts of light spectrum, and we calculated normalised differential vegetation index (NDVI). We used information statistics proposed by Juhász-Nagy to study the association between spatial patterns of production and species composition. Since information statistical functions applied require binary data, we transformed NDVI data into one or several binary variables. We found that not only dominant species but subordinate gap species were also associated to high biomass, although the strength of association varied across scales. Most of the significant associations were detected at fine scales, from 0.05 to $0.25 \mathrm{~m}$. At the scales commensurable with quadrat sizes usually applied in grasslands, i.e., from 0.5 to $2.0 \mathrm{~m}$, we could hardly find any significant associations between species composition and biomass. We concluded that the novel methods applied proved reliable for studying fine-scale relationships between species composition and biomass.
\end{abstract}

Nomenclature: Simon 1992

Abbreviations: ASB - Association between species and biomass; AFB - Association between florulae and biomass; D - Level of detailedness of transformed NDVI data; DS - Difference in species richness; FD - Florula diversity.

\section{Introduction}

Productivity and composition are two community level characteristics of vegetation; operative definitions and estimations of these characteristics, as well as the measuring of the relation between them, are central issues in vegetation science (Rosenzweig and Abramsky 1993, Waide et al. 1999). Most of the studies in the latter field are at regional or continental scales, or deal with experimental communities, the scale of sampling is often arbitrary, the composition is usually represented by the species richness, and the results are inconsistent (Johnson et al. 1996, Lawton 1999, Waide et al. 1999). Virtually there are no studies at fine scales, applying pattern-to-pattern approach (Bartha et al. 1997), i.e., comparing patterns of productivity and species compositions. We intended to elaborate a framework of methods which is (a) applicable to grassland communities, (b) useful for comparing patterns, and (c) scalable at the range of scales of the matrixand-gap pattern.
For estimating productivity, various approaches are applied from measuring the limiting or conditioning factors of productivity like available soil moisture or nutrients, light, temperature, through integrated productivity terms like gross or net primary production, up to direct measurement of leaf area index or different biomass terms like total or green; total, aboveground, or belowground biomass (Milner and Elfyn Hughes 1968, Gower et al. 1999). Most of the measurement methods associated with the above approaches are too labour intensive to apply them to detect fine-scale pattern of productivity, e.g., at 0.05 by $0.05 \mathrm{~m}^{2}$ resolution. Consequently, this pattern is virtually not studied. Wilson et al. (2000) analysed composition of biomass of species in semi-arid grasslands at resolution of 0.10 by $0.10 \mathrm{~m}^{2}$ using destructive sampling. However, the method they applied was extremely labour intensive and non-repeatable.

Field-level remote sensing can provide non-destructive techniques for repeated estimation of leaf area index 
or aboveground green biomass at extremely fine spatial resolution $(<0.05 \mathrm{~m})$. Quantitative measurements of light interception and reflectance complement visual estimation methods, e.g., canopy cover or basal area estimation, and are broadly employed in agricultural and forest ecology.

The reflectance methods are based on the differential spectral interactions of visible and near infrared radiation to green vegetation: red light is strongly absorbed by photosynthetic pigments and near infrared (NIR) light is strongly scattered by the spongy mesophyll (Gausman 1977). Normalized differential vegetation index (NDVI) was designed to estimate the quantity of chlorophyllous tissue in the canopy (Tucker 1979, Pinar and Curran 1996). Recently, digital camera sensitive to both red and NIR light has been developed for monitoring vegetation.

Composition of vegetation is usually characterised by diversity terms. Currently, species richness has been overwhelmingly applied as a diversity measure, although this is a rather rough estimator of the compositional richness of vegetation because only the number of elements of a complex pattern is enlisted without studying the relations between the elements (Juhász-Nagy 1967). More sensitive estimators are based on the frequency distribution of species, life forms or architectural elements. Applying Juhász-Nagy’s approach (Juhász-Nagy and Podani 1983), we use compositional diversity, which is based on the frequency distribution of local species combinations.

Juhász-Nagy elaborated a family of information statistical models, which we call JNP-models or functions. Using these models, one can calculate the entropy of species by sampling units matrices containing presence/ absence, i.e., binary data. The models provide various measures for characterising species composition, including pairwise and multiple associations between species.

JNP-models can also be applied to estimate the association between multispecies pattern and any auxiliary variable or variables (Bartha 2001). Since those models are elaborated for analysing binary data, the auxiliary variable or variables should be binary as well. In this paper, we suggest transforming interval type biomass estimation (i.e., NDVI) data into binary variable or variables, and applying JNP-models for measuring association between the transformed biomass and the originally binary vegetation data.

Transect methods are widely used in fine-scale studies of vegetation pattern and dynamics (Greig-Smith 1983, Bartha and Horváth 1987, Palmer and van der Maarel 1995). There are two special advantages of the transect methods. One is that changing spatial scale is relatively easy by either merging the adjoining sampling units, or applying different separation distances between sampling units. The other advantage is that various randomisations can be applied for statistical tests by shifting and mixing the sampling units (Manly 1997). Using circular transects, i.e., 'trainsects', scaling and neutral modelling can be carried out with no edge effects at the ends of the transects (Palmer and van der Maarel 1995, Bartha and Kertész 1998).

In this paper, we suggest a novel operative framework for sampling and analysing fine-scale patterns of biomass and composition of grassland vegetation, and for detecting the relationships between them across a range of scales. We describe the methods of this framework in detail, and we aim to demonstrate their applicability in a study on relations between species composition and biomass of an open perennial sand grassland.

\section{Materials and methods}

\section{Study area}

The study area is a nature preserve $30 \mathrm{~km} \mathrm{NE}$ of $\mathrm{Bu}-$ dapest, in the outskirts of Vácrátót village, in the valley of Tece creek. Its dominant vegetation type is open perennial sand grassland Festucetum vaginatae danubiale (Kárpáti and Kárpáti 1954) on slightly humic calcareous sand soil. The climate is temperate with frequent droughts in any season, especially in late summer and early autumn (mean annual precipitation: $650 \mathrm{~mm}$, mean daily temperature in January: $-1.5^{\circ} \mathrm{C}$, in July: $20.5^{\circ} \mathrm{C}$ ).

The vegetation is co-dominated by $F$. vaginata and Stipa borysthenica tussocks, which we consider as 'matrix species'. The gaps between the tussocks are mostly covered by either litter of the dominant grasses or by moss (Tortula ruralis), and there are a number of annual species, some forbs and an ephemeral perennial grass, Poa bulbosa. We consider moss, lichens, and small bodied species as 'gap species'. There are also numerous dead or partially dead tussocks of $F$. vaginata, indicating recent changes in the composition of the grassland.

\section{Sampling design and vegetation data recording}

We settled two topologically circular transects in two neighbouring patches of the grassland. In the patch of transect 1 , the abundance of the dominant Festuca vaginata is higher than in the other patch. S. borysthenica occurs along both transects. Moss cover is almost complete in the gaps.

Each transect was $46 \mathrm{~m}$ long, being composed of 920 adjacent $0.05 \times 0.05 \mathrm{~m}^{2}$ elementary sampling units (Figure 1). The size of the elementary sampling unit is small 


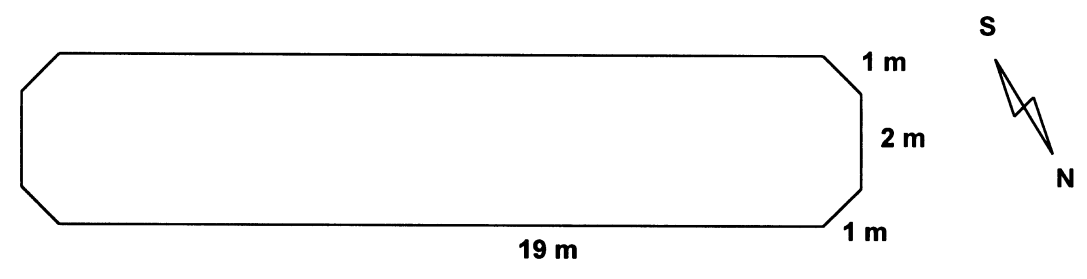

Figure 1. Transect topography.

enough to study the interactions between the populations at the scale of the individuals and clones (i.e., tussocks), and the number of sampling units is large enough for diversity estimations (Bartha and Horváth 1987). At each meter along the transects, we placed $40 \mathrm{~cm}$ long iron tubes into the soil in order to fix the exact location of the transects. The samples were taken in September 2000. In this period, after a severe drought from April to July, and rains in August and early September, the vegetation turned to green again, and the autumn and winter annual species began to grow.

Along the transects we recorded the occurrence of vascular plant species, and the occurrence of moss and lichen without indicating their species. (The mosses were almost exclusively $T$. ruralis; the lichens were a mixture of four Cladonia and one Parmelia species.) We will use the term 'species' for moss and lichen data in what follows.

In order to analyse vegetation at various scales, we applied a series of merged sampling units: $2,3,4,5,8,10$, $15,20,30,40,55,99,200,365$. We expressed the scale with the lengths of the sampling units in $\mathrm{m}: 0.05,0.10$, $0.15,0.20,0.25,0.40,0.55,0.75,1.00,1.50,2.00,2.75$, $4.95,10.00,18.25$. This series is approximately logarithmic. The merged sampling units are overlapped with each other. We applied complete resampling, i.e., each merged sampling unit appeared once in the samples, thus the number of sampling units was 920 at each scale.

\section{Field remote sensing}

We estimated the green biomass along the transects by Dycam ADC4 digital camera (C Dycam Inc.). The camera contains a pair of $496 \times 365 \mathrm{CCD}$ arrays with spectral ranges of $0.6-0.75 \mu \mathrm{m}$ for the red sensor and 0.75 - $1.25 \mu \mathrm{m}$ for the NIR array. A Wratten 29 red filter is used to block radiation below $0.6 \mu \mathrm{m}$ (White et al. 2000). We used the camera in half-size mode to produce pictures measuring $248 \times 182$ pixels. We shot in nadir view from a height of approximately $160 \mathrm{~cm}$ to produce images of spots, approximately $65 \times 48 \mathrm{~cm}$. Each picture covered a $50 \mathrm{~cm}$ interval of transect; thus, 92 pictures covered one transect. (The storage capacity of the camera was 96 pictures at the applied resolution and compression level.) A metal ruler was placed within the field of view in order to estimate the reflectance values in the $0.05 \times 0.05 \mathrm{~m}^{2}$ sam- pling units. All pictures were taken approximately close to local solar noon.

The pictures were downloaded from the camera and stored by Dycam Picture Viewing Utility Version 4.51 (C) Dycam Inc.), and the reflectance values were read from the picture by BRIV32 32 bit Band Ratioing Image Viewer Version 1.61 (C Steve Heinold). Calculation of the reflectance ratio requires calibration to the incoming light. Thus, for each picture, we included a $5 \times 5 \mathrm{~cm}$ Teflon( panel which reflects about $80 \%$ of both red and NIR illumination. From the panel we read $R_{\text {panel }}$ and $N I R_{\text {panel }}$ reflectance values, and $R_{o b s}$ and $N I R_{o b s}$ values from 10 small quadrats beside the ruler.

The reflectance ratios for the small quadrats were calculated as follows:

$R_{\text {ratio }}=0.8 R_{\text {obs }} / R_{\text {paneb }}$

$N I R_{\text {ratio }}=0.8 N I R_{\text {obs }} / 0.5\left(R_{\text {panel }}+N I R_{\text {pane }}\right)$

The constant 0.8 was applied because the Teflon panel reflects about $80 \%$ of the illumination. The $N I R_{\text {ratio }}$ was calculated not only from $N I R_{\text {panel }}$ and $N I R_{o b s}$, but using $R_{\text {panel }}$ as well, because the $N I R_{\text {panel }}$ data were too sensitive to changes in cloud cover and exposure time, and consequently the vegetation indices (see below) significantly depended on the $R_{\text {panel }} / N I R_{\text {panel }}$ ratio. The use of the above equation eliminates this dependence.

The reflectance values also significantly depended on the position of the elementary sampling units inside the pictures. The units, which were closer to the edges of the picture, were significantly darker than those in the middle part of the picture. The difference between the positions also depended on the compass direction of transect, evidently because of the direction of sunlight. To avoid the effect of positions, we standardized the reflectance values in order to make the average of reflectances for each inside-picture position (i.e., first position from east, second position of east, etc.) equal. We carried out this standardisation only in case of pictures taken along the longer sides of the transects (see Figure 1), where compass direction and the direction of sunlight were constant.

From the corrected reflectance values we calculated NDVI (normalised differential vegetation index), which 
is the most widely used spectral vegetation index, a surrogate for aboveground green biomass or leaf read index:

$\mathrm{NDVI}=\left(N_{R_{\text {ratio }}}-R_{\text {ratio }}\right) /\left(\right.$ NIR $\left.R_{\text {ratio }}+R_{\text {ratio }}\right)$

NDVI calculated from Dycam camera data had been calibrated in case of open perennial sand grassland vegetation in Kiskunság against dry weight of aboveground green biomass $\left(\mathrm{R}^{2}=0.65, n=56\right.$; Henebry et al. 2000$)$.

In case of merged sampling units, we calculated average $R_{\text {ratio }}$ and NIR ratio from $R_{\text {ratio }}$ and NIR $R_{\text {ratio }}$ measured in elementary sampling units, and then recalculated NDVI.

We transformed interval type NDVI data into binary form by applying a threshold. We assigned 0 to the values below the median, and 1 to the others. In addition to this method, we used a series of transformations with growing level of detailedness $(D)$ of transformed data. We divided the NDVI data range into $2^{D}$ equal parts and assigned a binary vector to values falling into a certain part of the range. For example, in case of $D=3$, we cut the range into $2^{3}=8$ parts, and assigned vector $\{0,0,0\}$ to the first part of the range, $\{0,0,1\}$ to the second, $\{1,1,1\}$ to the eighth. Thus, we got $D$ binary data variables from the NDVI data. We applied $D=1$ (cutting by median), 2 (cutting by quartiles), 3 and 4 . In case of $D=4$, the subranges were not exactly equal; they consisted of 57 or 58 elements. This method applied only technically differs from transform-

\section{Original data}

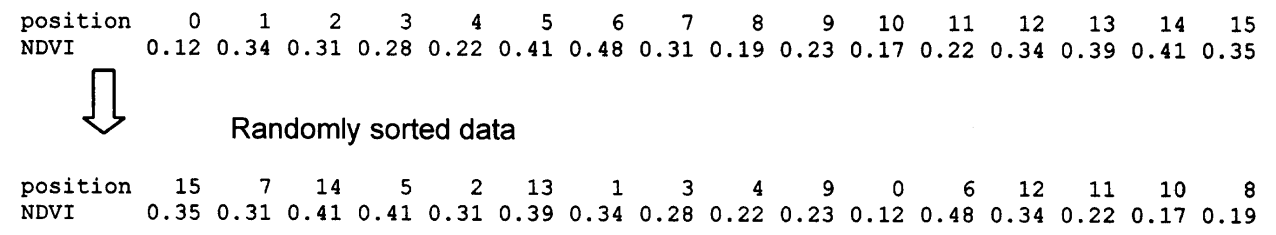

Data sorted by ascending NDVI values Assigning binary vectors

\begin{tabular}{|c|c|c|c|c|c|c|c|c|c|c|c|c|c|c|c|c|}
\hline position & 0 & 10 & 8 & 4 & 11 & 9 & 3 & 7 & 2 & 1 & 12 & 15 & 13 & 14 & 5 & 6 \\
\hline NDVI & 0.12 & 0.17 & 0.19 & 0.22 & 0.22 & 0.23 & 0.28 & 0.31 & 0.31 & 0.34 & 0.34 & 0.35 & 0.39 & 0.41 & 0.41 & 0.48 \\
\hline d1 & 0 & 0 & 0 & 0 & 0 & 0 & 0 & 0 & 1 & 1 & 1 & 1 & 1 & 1 & 1 & \\
\hline d2 & 0 & 0 & 0 & 0 & 1 & 1 & 1 & 1 & 0 & 0 & 0 & 0 & 1 & 1 & 1 & \\
\hline d3 & 0 & 0 & 1 & 1 & 0 & 0 & 1 & 1 & 0 & 0 & 1 & 1 & 0 & 0 & 1 & \\
\hline
\end{tabular}

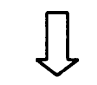

Data sorted back by original positions

$\begin{array}{lrrrrrrrrrrrrrrrr}\text { position } & 0 & 1 & 2 & 3 & 4 & 5 & 6 & 7 & 8 & 9 & 10 & 11 & 12 & 13 & 14 & 15 \\ \text { NDVI } & 0.12 & 0.34 & 0.31 & 0.28 & 0.22 & 0.41 & 0.48 & 0.31 & 0.19 & 0.23 & 0.17 & 0.22 & 0.34 & 0.39 & 0.41 & 0.35 \\ \text { d1 } & 0 & 1 & 1 & 0 & 0 & 1 & 1 & 0 & 0 & 0 & 0 & 0 & 1 & 1 & 1 & 1 \\ \text { d2 } & 0 & 0 & 0 & 1 & 0 & 1 & 1 & 1 & 0 & 1 & 0 & 1 & 0 & 1 & 1 & 0 \\ \text { d3 } & 0 & 0 & 0 & 1 & 1 & 1 & 1 & 1 & 1 & 0 & 0 & 0 & 1 & 0 & 0 & 1\end{array}$

Figure 2. A simple example for the transformation of a 16-element NDVI data vector. Here we apply $D=3$. $\mathrm{d} 1$, $\mathrm{d} 2$, and $\mathrm{d} 3$ are the resulting binary variables. Note that $\mathrm{d} 1$ is the result of $D=1, \mathrm{~d} 1$ and $\mathrm{d} 2$ are the results of $D=2$. ing NDVI data into nominal variables of $2^{D}$ values. Applying transformation we should not produce significant associations as artefacts, although it causes some loss of information.

A standard method for cutting a data vector at a threshold is to sort the data by ascending order and then to cut the vector at the serial positions where the data cross the threshold. If there are equal values in the data vector, and those values occur around the threshold, the data with lower serial positions will fall below the threshold, i.e., the positions and the result of thresholding will interfere. It is a consequence of application of the sorting procedure, which does not change the sequence of the tied values. To avoid this effect, we first randomly sorted the NDVI data and then transformed them. We show a simple example

\section{Compositional diversity and productivity-composition relations}

For measuring the compositional diversity of species combinations, we applied a function called florula diversity (FD). This is the entropy of the species combinations $(H)$ estimated by calculating Shannon-diversity of the frequency distribution of the species combinations:

$\widehat{H}=\sum_{i=0}^{2^{s}-1} \frac{n_{i}}{m} \log _{2} \frac{n_{i}}{m}$

where $n_{i}$ is the frequency of the $i$-th species combination, the number of sampling units is $m, s$ is the number of spefor the transformation of NDVI data in Figure 2. 


\begin{tabular}{|c|c|c|c|c|c|c|c|c|c|c|c|}
\hline d1 & 1 & 1 & 1 & & & 1 & & & & & 1 \\
\hline d? & 1 & 1 & & & & 1 & 1 & 1 & 1 & 1 & \\
\hline & 1 & 1 & 1 & & 1 & 1 & & & & & \\
\hline & 1 & & 1 & & & 1 & 1 & 1 & 1 & & 1 \\
\hline & 1 & & 1 & 1 & & & 1 & 1 & & & \\
\hline
\end{tabular}

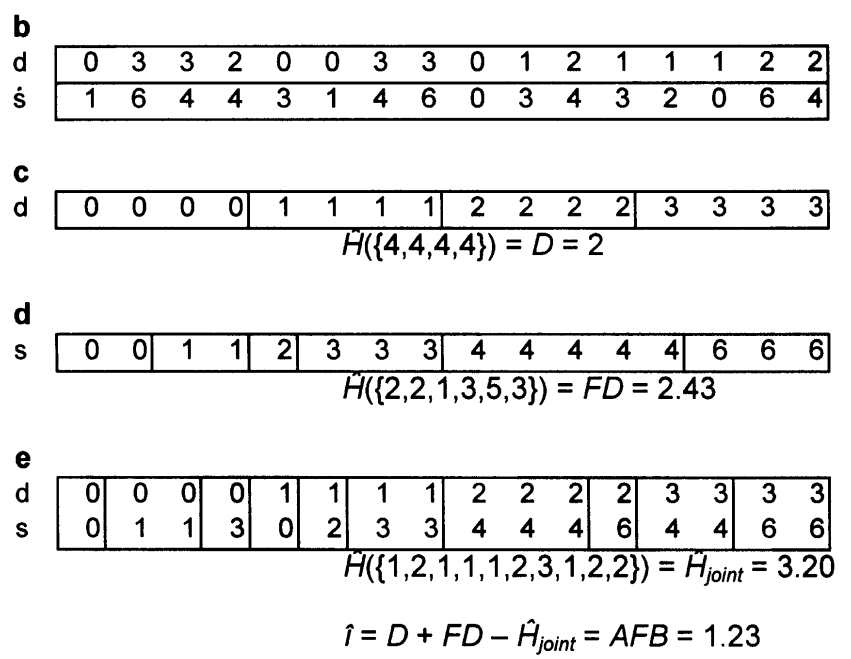

Figure 3. A simple example for the calculation of AFB. a. Biomass and species data. $\mathrm{d} 1$ and $\mathrm{d} 2$ are transformed NDVI data; $\mathrm{s} 1, \mathrm{~s} 2$, and s2 are species data. b. Biomass data combinations (d) and species combinations (s). $\mathrm{d}$ and s are decimal representations of $\{\mathrm{d} 1, \mathrm{~d} 2\}$ and $\{\mathrm{s} 1, \mathrm{~s} 2, \mathrm{~s} 3\}$ binary column vectors, respectively. c. Biomass data combinations sorted in ascending order to show their frequency distribution and calculation of their entropy, $D$. d. Species combinations sorted in ascending order and calculation of their entropy, FD. e. Combinations of biomass data combinations and species combinations sorted in ascending order, calculation of their entropy, $H_{j o i n t}$, and of the mutual information between biomass data and species combinations, AFB.

cies, and $i$ ranges from 0 (i.e., no species present) to $2^{s}-1$ (i.e., all species present). Index $i$, written in binary form, directly shows which species combination is accounted. For example, in case of 4 species, index 5 means vector $\{0,1,0,1\}$, i.e., the species 2 and 4 are present, the other two are absent. The unit of FD is bit. In case of a univariate (i.e., single-species) vector, there are only two species combinations, presence or absence, and the maximum of $H$ is 1 , when half of the data are of 'presence' value. The theoretical maximum of FD is $s$ : if all species occur in half of the sampling units and are independent from one another. FD drawn as a function of sampling unit area is practically always unimodal (Tóthmérész and Erdei 1992). The position of its maximum is called maximum area. In case of transformed biomass data, which consist of vectors d1, d2, etc. (Figure 2), $\hat{H}$ is equal to the level of detailedness $D$, independently on the spatial scale.

We measured the association between two data sets (either univariate or multivariate data sets) by means of the mutual information $\hat{I}$ of the two variables:

$$
\widehat{I}=\hat{H}_{1}+\widehat{H}_{2}-\hat{H}_{j o i n t}
$$

where $\hat{H}_{1}$ and $\hat{H}_{2}$ are the entropies of data sets 1 and 2 and $\hat{H}_{\text {joint }}$ is the entropy of the unified data set. The maximum of $\hat{I}$ is the lower value of the two entropies. In practice, we compose a matrix consisting of the row vectors of data sets 1 and 2, and calculate the entropy of this unified matrix, and then subtract the result from the sum of entropies of the two constituents of the unified matrix. We applied this formula in two ways. We calculated the association between transformed biomass data and single species data (ASB, Association between Species and Biomass), and also between transformed biomass data and multispecies data [AFB, Association between Florulae (i.e., species combinations) and Biomass]. In the latter case, we treat the transformed NDVI data as 'pseudospecies', and we substitute FD for $\hat{H}$ of the species composition data and $D$ for $\hat{H}$ of the transformed NDVI data (see Figure 3):

$$
\widehat{I}=\mathrm{FD}+D-\hat{H}_{j o i n t}
$$

Besides using information statistical models, we studied the impact of biomass on species richness. In case of cutting the NDVI data at their median $(D=1)$, we counted 
species occurrences falling into the below-median and above-median NDVI subrange, and calculated the difference in the average species richness between the two subranges (DS, Difference in Species richness).

All measures were calculated at each scale. At coarser scales, a species, infrequent in the elementary sampling units, would occur in many merged sampling units. Consequently, the resultant diversity measures at coarser scales would be very sensitive to the distribution of the rare species (Tóthmérész and Erdei 1992, Bartha et al. 1995). To avoid this phenomenon, we omitted from all analyses the species having less than 10 occurrences in the elementary sampling units.

Circular transects provide various opportunities for randomisations to test the significance of diversity and association by shifting and mixing species occurrences (Palmer and van der Maarel 1995, Bartha and Kertész 1998). Association can occur as a consequence of autocorrelation of the biomass, or spatial aggregation of the species combinations; one can take this effect into consideration by randomisation, thus the significance level of association will be free of this effect. We applied random shifting, which preserved the separate spatial patterns of species composition and biomass. We randomly shifted the species data while transformed NDVI data remained in their original position. In order to get $5 \%$ significance level, we applied 1000 randomisations with replacement (i.e., the same shifting could occur several times).

\section{Results}

Overall species richness, aboveground biomass, and florula diversity

We found 32 species in the two transects altogether; 20 species were recorded in transect 1 , and 23 species in transect 2 (moss and lichens are counted as two species). The numbers of frequent species (i.e. whose frequency

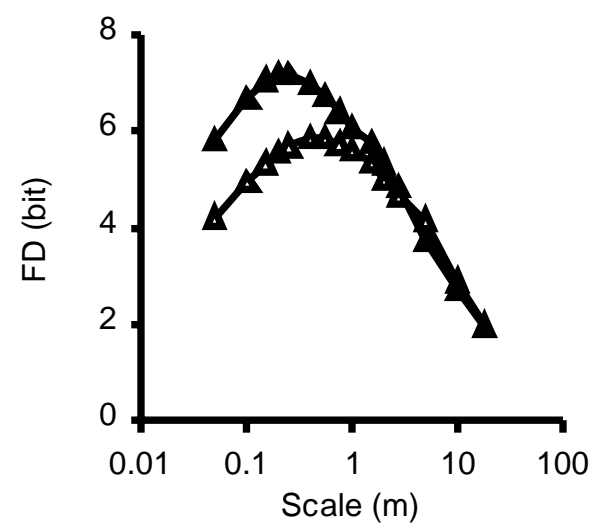

Figure 4. Florula diversity (FD) of transect 1 (lower curve) and 2 (upper curve). was more than or equal to 10 in the elementary sampling units) were 11 and 14, respectively. The NDVI of transect 1 calculated from average reflectances was 0.271 , and of transect 2 was 0.328 . Applying the calibration proposed by Henebry et al. (2000), they stand for $68.9 \mathrm{~g} / \mathrm{m}^{2}$ and $109.6 \mathrm{~g} / \mathrm{m}^{2}$ dry green biomass, respectively.

Florula diversity values are shown in Figure 4. In case of transect 1, the maximum of FD is 5.9 bit at a scale of $0.40 \mathrm{~m}$, in case of transect 2, 7.2 bit at a scale of $0.25 \mathrm{~m}$. Thus, transect 2 has more species, higher FD at smaller scale, and higher biomass than transect 1 .

\section{Associations between species patterns and biomass}

Table 1 shows the abundances of frequent species and their distribution among elementary sampling units of below-median and above-median NDVI values. The abundance of the dominant Festuca vaginata was lower in transect 2, having more biomass. This indicates that this species alone did not contribute essentially to the overall biomass of the community. The most important species in determining overall biomass among the larger bodied plants could be Stipa borysthenica, whose frequency was twice higher in transect 2 than in transect 1 , and its distribution was strongly shifted towards sampling units of above-median NDVI at finer scales.

The recorded individuals of Euphorbia cyparissias, whose frequency was ten times higher in transect 1 having lower biomass than in transect 2 having higher biomass, were either almost dry shoots or seedlings, so this species has insignificant contribution to green biomass. Lichens, Poa bulbosa, Arenaria serpyllifolia, and Medicago minima were much more frequent in transect 2 than in transect 1 . These species together could contribute to the higher biomass of transect 2 , even if they are considered as subordinated gap species.

Table 2 shows the pattern of significant associations of species with transformed NDVI data (ASB) at each scale and level of detailedness. Five species in transect 1 and nine in transect 2 had at least one significant association. Most of the significant associations occured at finer scales, from 0.05 to $0.25 \mathrm{~m}$. In case of transect 1,43 of the total of 220 tests at scales 0.05 to 0.25 (11 species by 5 scales by 4 levels of detailedness of transformed NDVI data) and 72 of the total of 280 for transect 2 were significant. The number of significant associations at $D=1$ was less than for the other levels of detailedness (31 at $D=1$ vs. 38,37 , and 36 at $D=2,3$, and 4 , respectively).

The patterns at different levels of detailedness of transformed NDVI data are similar, but transformation at $D=1$ alone is not sufficient to observe associations (as in 
Table 1. Frequencies of occurrences of species in elementary sampling units and their distribution among below- and abovemedian NDVI subranges $(D=1)$. All: frequencies in all (920) elementary sampling units. NDVI-: frequencies in elementary sampling units which have below-median NDVI values. NDVI+: frequencies in elementary sampling units which have above-median NDVI values. Boldface refers to species which have significant $(\mathrm{p}<0.05)$ ASB at $D=1$ and at the scale of elementary sampling units $(0.05 \mathrm{~m})$.

\begin{tabular}{|l|rrr|rrr|}
\hline & \multicolumn{3}{|c|}{ Transect 1 } & \multicolumn{4}{|c|}{ Transect 2 } \\
species & All & NDVI- & NDVI+ & All & NDVI- & NDVI+ \\
\hline moss & 636 & 315 & 321 & 662 & 290 & $\mathbf{3 7 2}$ \\
lichen & 29 & 13 & 16 & 343 & 150 & 193 \\
Festuca vaginata & 256 & 99 & 157 & 111 & 48 & 63 \\
Stipa borysthenica & 45 & 9 & 36 & 97 & 24 & 73 \\
Poa bulbosa & 103 & 37 & 66 & 316 & 132 & 184 \\
Carex stenophylla & 14 & 7 & 7 & & & \\
Centaurea arenaria & 49 & 10 & 39 & & & \\
Erysimum diffusum & & & & 38 & 19 & 19 \\
Euphorbia segueriana & 225 & 117 & 108 & 22 & 11 & 11 \\
Potentilla arenaria & & & & 33 & 7 & 26 \\
Thymus glabrescens & 15 & 3 & 12 & & & \\
Arenaria serpyllifolia & 37 & 21 & 16 & 204 & 93 & 111 \\
Eragrostis scabra & & & & 13 & 2 & 11 \\
Medicago minima & & & & 144 & 66 & 78 \\
Plantago indica & 24 & 12 & 12 & & & \\
Silene otites & & & & 20 & 11 & 9 \\
Tribulus terrestris & & & & 17 & 4 & 13 \\
Indet. & & & & 10 & 7 & 3 \\
\hline
\end{tabular}

Table 2. Significant associations between species and NDVI (ASB) at different scales and at different levels of detailedness $(D)$ of transformed NDVI data. Numbers $1,2,3$, and 4 show at which $D$ was the association significant $(\mathrm{p}<0.05)$.

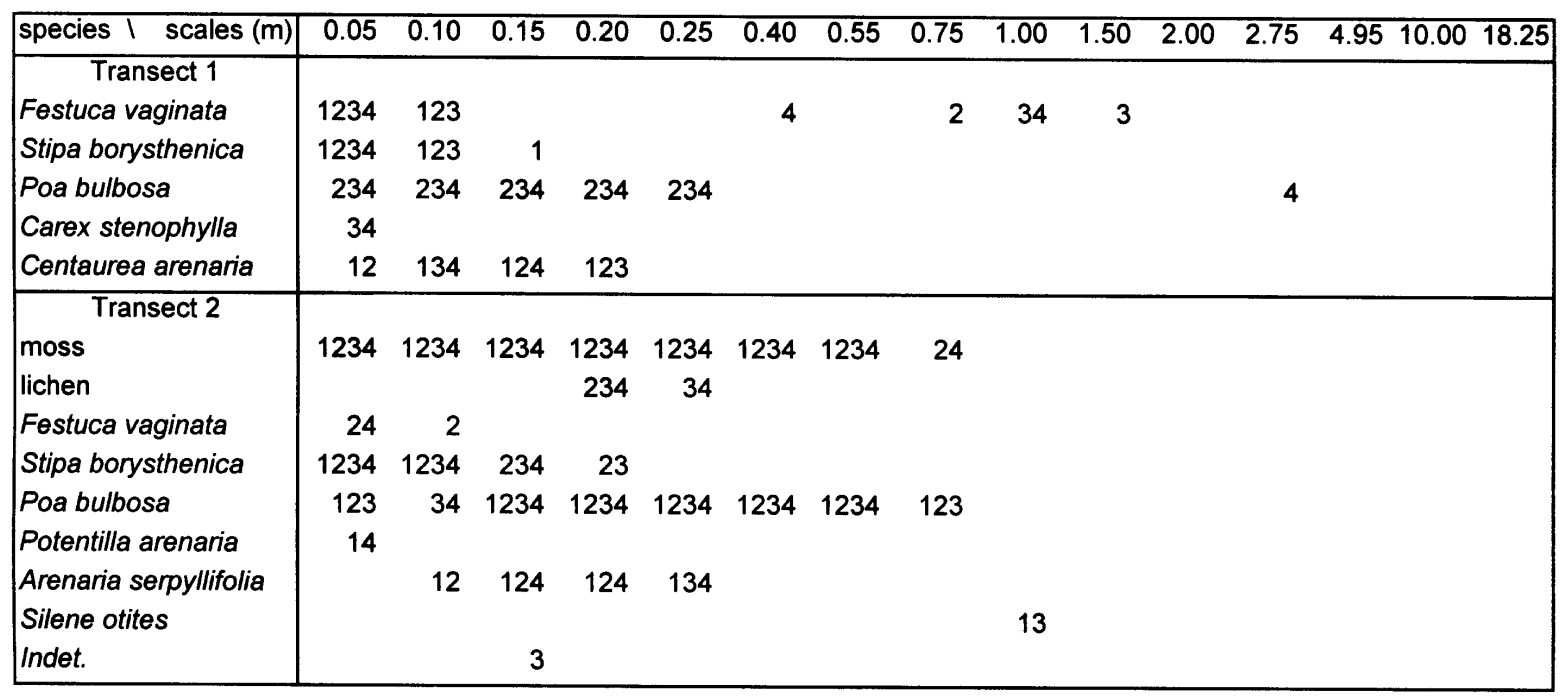

case of Poa bulbosa in transect 1). About half of the species were tending to associate to a certain range of green biomass at fine scales. This association was rather simple: the biomass was higher where those species occurred. Either the two matrix species or gap species could show this pattern, except Silene otites (transect 2, D=1, at 1.00 m), which was negatively associated with transformed NDVI.

Associations between species combinations and biomass

The pattern of significant AFB values was similar to ASBs, i.e., they occurred at finer scales, and transect 2 had 

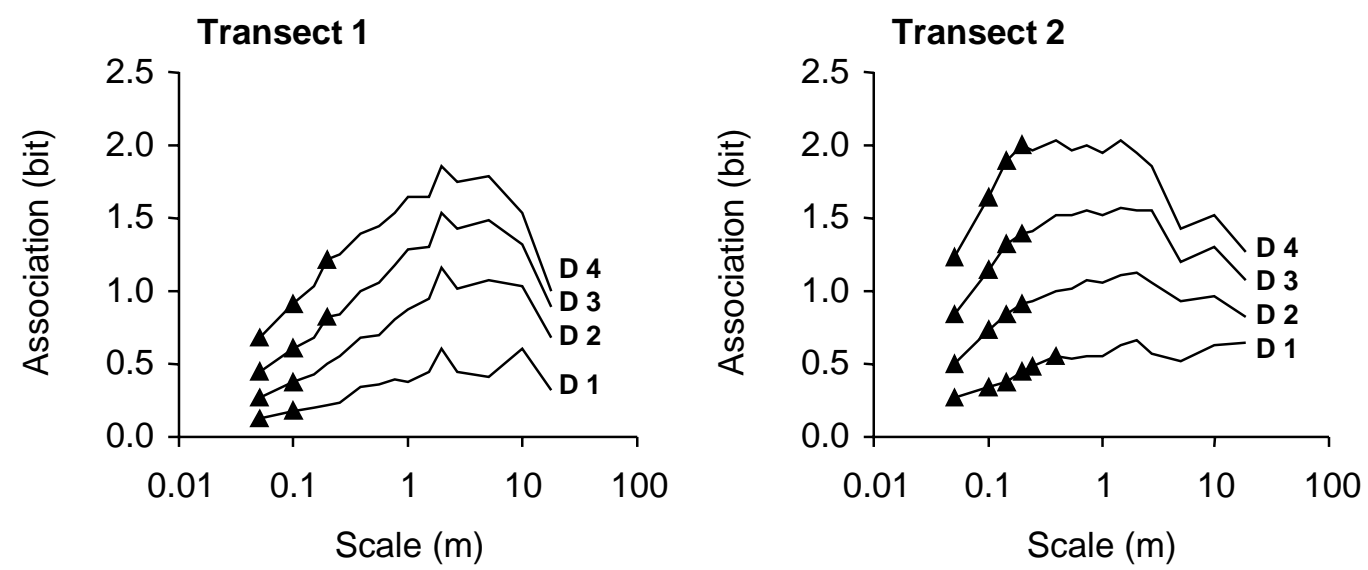

Figure 5. Associations between species combinations and NDVI (AFB) at different scales and levels of detailedness of transformed NDVI data $(D=1$ to $D=4)$. Triangles stand for significant associations $(\mathrm{p}<0.05)$.
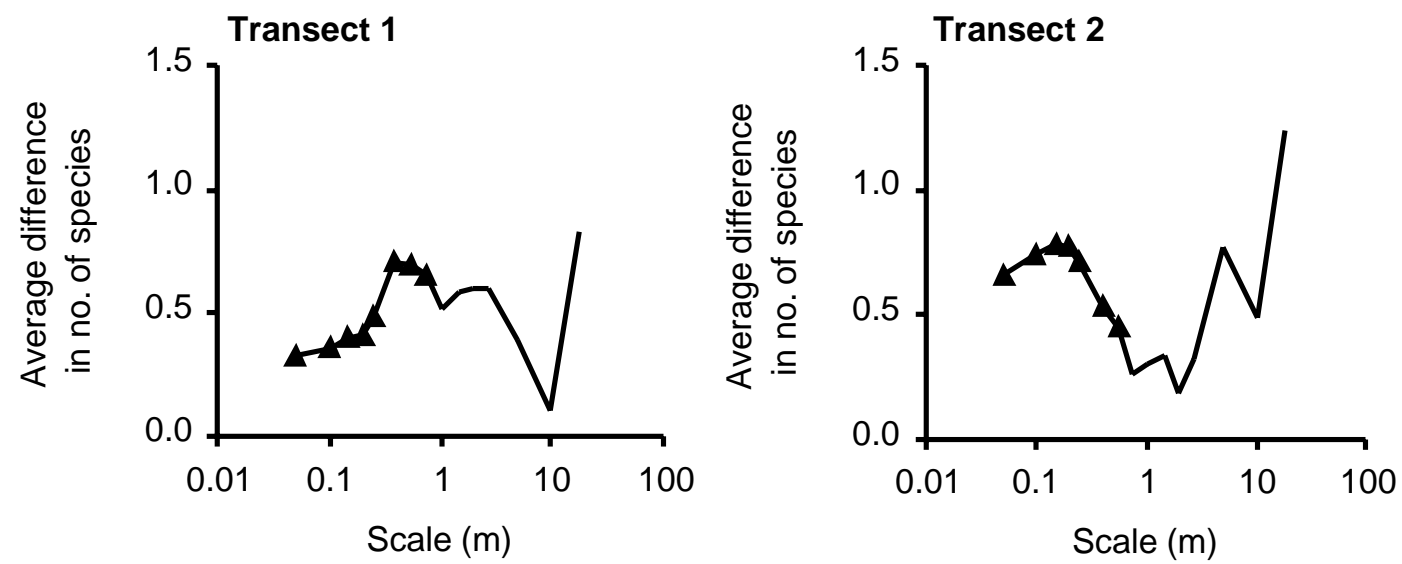

Figure 6. Differences in species richness between above- and below-NDVI sampling units (DS). Triangles denote significant $(\mathrm{p}<0.05)$ differences.

more significant associations (Figure 5). The AFB functions tend to increase proportionally with $D$. The difference between AFB functions of transect 1 and transect 2 was similar to the differences in their FD functions, i.e., transect 2 had higher values at finer scales and higher overall maxima. Looking only at the significant associations we found that AFBs of transect 2 were higher, and occurred at broader range of scales.

\section{Relationships between biomass and species richness}

The average differences in species richness between sampling units of above- and below-median NDVI (DS) show local maxima at fine scales (Figure 6). All values are positive, i.e., the higher the biomass the higher the average species richness. Similarly to FD and AFB functions, the first local maximum of DS of transect 2 was higher than that of transect 1 ( 0.783 vs. 0.704$)$, and oc- curred at finer scale $(0.15$ vs. $0.40 \mathrm{~m})$. In case of transect 2 , there was a sharp decrease of DS at scales coarser than $0.15 \mathrm{~m}$, down to 0.45 at $0.55 \mathrm{~m}$. The DS values at coarser scales are not significant, thus we did not take them into consideration. However, the result shows that at scale around $1 \mathrm{~m}$, which is commensurable with the often applied $0.5 \times 0.5 \mathrm{~m}^{2}$ or $1 \times 1 \mathrm{~m}^{2}$ sampling quadrats, we did not find significant differences in species richness between high and low biomass plots.

\section{Discussion}

\section{Limitations of methods applied}

Estimation of NDVI. Measuring NDVI in $0.05 \times 0.05 \mathrm{~m}^{2}$ sampling units by digital camera is definitely beyond the range of applicability offered by the manufacturer of the Dycam ADC4 camera (Agricultural Camera User's 
Guide). The most important problems we experienced are mentioned in the "Materials and methods" section. The dependence of the calculated NDVI on the inside-picture positions was easy to handle by means of standardization. On the other hand, the dependence of NDVI on the R/NIR ratio measured on the Teflon panel was incomprehensible for us. To avoid this effect, we applied a non-standard reflectance calculation method. However, using a small calibration data base of 24 NDVI and aboveground dry green biomass measurements, we obtained a determination coefficient $\mathrm{R}^{2}=0.256$ with the standard calculation method, while $\mathrm{R}^{2}=0.354$ with our non-standard method

In tall and multi-layered vegetation, the estimation of NDVI by digital camera in $0.05 \times 0.05 \mathrm{~m}^{2}$ sampling units is hardly possible, because closer to the side of the picture more area is covered up by the taller plants from the neighbouring sampling units. Thus, application of digital camera for such fine-scale biomass estimations is reliable only in short-grass vegetation.

A special problem in biomass estimation by reflectance measurements is caused by Tortula ruralis, which changes its colour according to its moisture status. This moss is active only in wet weather or in early morning (Csintalan et al. 2000). When inactive, its colour turns to brown. In this state, separate calibration would be needed for estimation of biomass of this moss by NDVI (Henebry 1999, unpublished). We used NDVI data directly in our analyses, i.e., without separate calibration for T. ruralis, thus the biomass of moss cover was poorly estimated.

Randomisation for testing of significance of statistics. In case of limited spatial data sets, randomisation is a very useful tool for testing the significance of statistics applied. However, the random shifting of species composition data interferes with our scaling method. As the sampling units are larger, the probability of overlapping between the original and shifted sampling units is larger too. In case of $2 \mathrm{~m}$ long sampling units along $46 \mathrm{~m}$ circular transect, the probability of at least $0.05 \mathrm{~m}$ overlap is $8.5 \%$, and at least $1 \mathrm{~m}$ overlap is $6.5 \%$. Thus, at coarser scales, it is less and less probable to get $\mathrm{p}<0.05$ significance of the statistics applied. We obtained most of the significant statistics at scales less than or equal to $1 \mathrm{~m}$ (see exceptions in Table 2), and the probability of statistics was close to the significance level in several cases at coarser scales. However, the pattern of significant associations obtained is not an artefact caused by the growing overlap of larger sampling units; at scales between 0.40 and $0.75 \mathrm{~m}$, where the overlap is negligible (around 1\%), we found much less significant associations than between 0.05 and $0.25 \mathrm{~m} \mathrm{(23}$ at three scales vs. 115 at five scales).
Relations between species composition and biomass. Our results agree with the widely accepted notion that, inside a plant community, diversity is higher in plots of higher biomass (Tilman et al. 1996, Hector et al. 1999). However, these results are in contradiction with our expectations, which came from the concept of matrix-and-gap structure of the open sand grassland studied. We hypothesised that the grassland consisted of monodominant matrix elements of high biomass, i.e., tussocks of dominant grass species and large bodied herbs, and species-rich low-biomass gaps with mosses, lichens, small bodied perennial and annual species. Thus, we expected that at the finest scales higher species richness would be found in low-biomass sampling units, and the typical gap species, like mosses, lichens, the small bodied ephemeral perennial Poa bulbosa, or the small annual Arenaria serpyllifolia would associate with low-biomass sampling units. In fact, many of the gap species were associated to highbiomass sampling units (see Tables 1 and 2).

One of the reasons of the contradictory result is that NDVI is an estimator of the density of photosynthetic pigments, not of any biomass fraction directly. The tussocks of dominant grasses, mainly of Festuca vaginata, contained many dried leaves, and only a small fraction of the leaves was green. By contrast, lichens and most of the small-bodied gap species were almost completely green. This contradiction between biomass and pigment density is not an artefact. Tuba et al. (personal communication) found in open sand grassland that in unfavourable weather conditions gap species could assimilate more carbon than matrix species.

The pattern of significant ASB values (Table 2) emphasises the importance of scales. The open perennial sand grassland cannot be considered a homogeneous mixture of plants. Most of the results show that the characteristic scale of the patchwork of the grassland, indicated by the maxima of the diversity and association functions applied (Juhász-Nagy and Podani 1983), is commensurable with the scale of the matrix-gap pattern.

Different species behave differently in that patchwork (Table 2). These results support the view of $\mathrm{Wu}$ and Loucks (1995) that there are different patchworks for different processes in the grassland community. By means of the novel framework of methods applied, we detected that different species and different species combinations have different relations to biomass pattern. We could analyse "pattern to pattern" relations at a range of scales (Bartha et al. 1997). These relations are dynamic, thus we intend to follow our research with dynamic studies, based on repeated sampling of both species composition and biomass. The setup of sampling, including the non-de- 
structive biomass estimation, makes those studies possible.

Acknowledgements: We are grateful to Sándor Bartha, Ferkó Csillag, Geoffrey M. Henebry, and Beáta Oborny for their contribution in elaborating the novel methodology applied, and for comments on the draft. We thank György Kröel-Dulay, Gábor Ónodi and János Garadnai for their assistance in field work. This study was supported by the Hungarian Scientific Research Fund (OTKA T032319).

\section{References}

Agricultural Camera User 's Guide. 1988-1999. (C) Dycam Inc., USA.

Bartha, S. 2001. Spatial relationships between plant litter, gopher disturbance and vegetation at different stages of old-field succession. Appl.Veg. Sci. 4: 53-62.

Bartha, S. and F. Horváth. 1987. Application of long transects and information theoretical functions to pattern detection. I. Transect versus isodiametric sampling units. Abstracta Botanica 11: 9-26.

Bartha, S., S. M. Glenn, S. L. Collins and M. Kertész. 1995. Small scale spatial organization of tallgrass prairie vegetation along a topographic gradient. Folia Geobot. Phytotax. 30: 169-184.

Bartha, S., T. Czárán and I. Scheuring. 1997. Spatiotemporal scales of non-equilibrium community dynamics: a methodological challange. New Zealand J. Ecol. 21: 199-206.

Bartha, S. and M. Kertész. 1998. The importance of neutral models in detecting interspecific spatial associations from 'trainsect' data. Tiscia 31: 85-98.

Csintalan, Zs., Z. Takács, M. C. E. Proctor, Z. Nagy and Z. Tuba. 2000. Early morning photosynthesis of moss Tortula ruralis following summer dew fall in a Hungarian temperate dry sandy grassland. Plant Ecol. 151: 51-54.

Gausman, H.W. 1977. Reflectance of leaf components. Remote Sensing of Environment 6:1-9.

Gower S.T., C.J. Kucharik, J.M. Norman. 1999. Direct and indirect estimation of leaf area index, fAPAR and net primary production of terrestrial ecosystems. Remote Sensing of Environment 70: 29-51.

Greig-Smith, P. 1983. Quantitative Plant Ecology. $3^{\text {rd }}$ ed. University of California Press, Berkeley.

Hector, A., Schmid B., C. Beierkuhnlein, M. C. Caldeira, et al. 1999. Plant diversity and productivity experiments in European grasslands. Science 286: 1123-1127.

Henebry, G. M., D. G. Goodin, S. Bartha, Zs. Molnár, M. Kertész and E. Kovács-Láng. 2000. Biomass estimation in the sandy grasslands of the Kiskun ILTER, Hungary. LTER All Scientists Meeting, Snowbird, UT, August 2-4, 2000.

Johnson, K. H., K. A. Vogts, H. J. Clark, O. J. Schmitz, and D. J. Vogt. 1996. Biodiversity and the productivity and stability of ecosystems. Trends in Ecology and Evolution 11: 372-377.
Juhász-Nagy, P. 1967. On association among plant populations. Part 1. Multiple and partial association: a new approach. Acta Biologica Debrecina 5: 43-56.

Juhász-Nagy, P. and J. Podani. 1983. Information theory methods for the study of spatial processes and succession. Vegetatio 51: 129140.

Kárpáti, I. and V. Kárpáti. 1954. The aspects of the calciphylous turf (Fectucetum vaginatae danubiale) in the environs of Vácrátót. Acta Bot.Hung. 1: 129-157.

Lawton, J. H. 1999. Are there general rules in ecology? Oikos 84: 177-192.

Manly, B. F. J. 1997. Randomization, Bootstrap and Monte Carlo Methods in Biology. Chapman \& Hall, London. 2nd edition.

Milner, C. and R. Elfyn Hughes. 1968. Methods for the Measurement of the Primary Production of Grassland. IBP Handbook No. 6. Burgess and Son, Abingdon, UK.

Palmer, M. W. and E. van der Maarel. 1995. Variance in species richness, species association, and niche limitation. Oikos 73: 203213.

Pinar, A. and P. J. Curran. 1996. Grass chlorophyll and the reflectance red edge. International Journal of Remote Sensing 17:351358.

Rosenzweig, M. L. and Z. Abramsky. 1993. How are diversity and productivity related? In: R. E. Ricklefs and D. Schluter (eds.), Species Diversity in Ecological Communities: Historical and Geographical Perspectives. University of Chicago Press, Chicago. pp. 52-65.

Simon, T. 1992. A magyarországi edényes flóra határozója. Harasztok - virágos növények. Tankönyvkiadó, Budapest.

Tilman, D., D. Wedin and J. Knops. 1996. Productivity and sustainability influenced by biodiversity in grassland ecosystems. $\mathrm{Na}$ ture 379: 718-720.

Tóthmérész, B. and Zs. Erdei. 1992. The effect of species dominance on information theory characteristics of plant communities. $A b$ stracta Botanica 16: 43-47.

Tucker, C. J. 1979. Red and photographic infrared linear combinations for monitoring vegetation. Remote Sensing of Environment 8:127-150.

Waide, R. B., M. R. Willig, C. F. Steiner, G. Mittelbach, L. Gough, S. I. Dobson, G. P. Juday, R. Parmenter. 1999. The relationship between productivity and species richness. Annual Review of Ecology and Systematics 30: 257-300.

White, M. A., G. A. Asner, R. R. Nemani, J. L. Privette and S. W. Running. 2000. Measuring fractional cover and leaf area index in arid ecosystems: digital camera, radiation transmittance, and laser altimetry methods. Remote Sensing of Environment 74: 4557.

Wilson, J. B., J. B. Steel, J. E. Newman and W. M. King. 2000. Quantitative aspects of community structure examined in a semi-arid grassland. J. Ecol. 88: 749-756.

Wu, J. and O. L. Loucks. 1995. From balance of nature to hierarchical patch dynamics: a paradigm shift in ecology. Quarterly Rev. Biol. 70: 439-466. 